УДК 621.039 .5

\title{
ВЛИЯНИЯ РЕЖИМНЫХ ПАРАМЕТРОВ НА ЭНТАЛЬПИЮ ПОПЕРЕЧНЫХ ПОТОКОВ МЕЖДУ ЯЧЕЙКАМИ ПУЧКА СТЕРЖНЕЙ
}

Авраменко А.А., член-корреспондент НАН Украины, Кондратьева Е.А., канд. техн. наук, Ковецкая М.М., канд. техн. наук, Тыринов А.И., канд. техн. наук

Институт технической теплофизики НАН Украины, ул. Желябова 2а, Киев 03680, Украина

Представлено результати чисельного моделювання процесів тепломасообміну при течії двофазного потоку в семистрижневій збірці. Досліджено вплив зміни режимів течії на ентальпію поперечних потоків між комірками пучка стрижнів.
Представлены результаты численного моделирования процессов тепломассобмена при течении двухфазного потока в семистержневой сборке. Исследовано влияние смены режимов течения на энтальпию поперечных потоков между ячейками пучка стержней.
The results of numeral simulations of heat and mass transfer processes for the two-phase flow in the seven-rod assembly are presented. Influence of flow regime changeover on enthalpy of cross-flow between the cells of the rod bundle are investigated.

Библ. 14 , рис. 4.

Ключевые слова: численное моделирование, семистержневая сборка, энтальпия поперечных потоков.

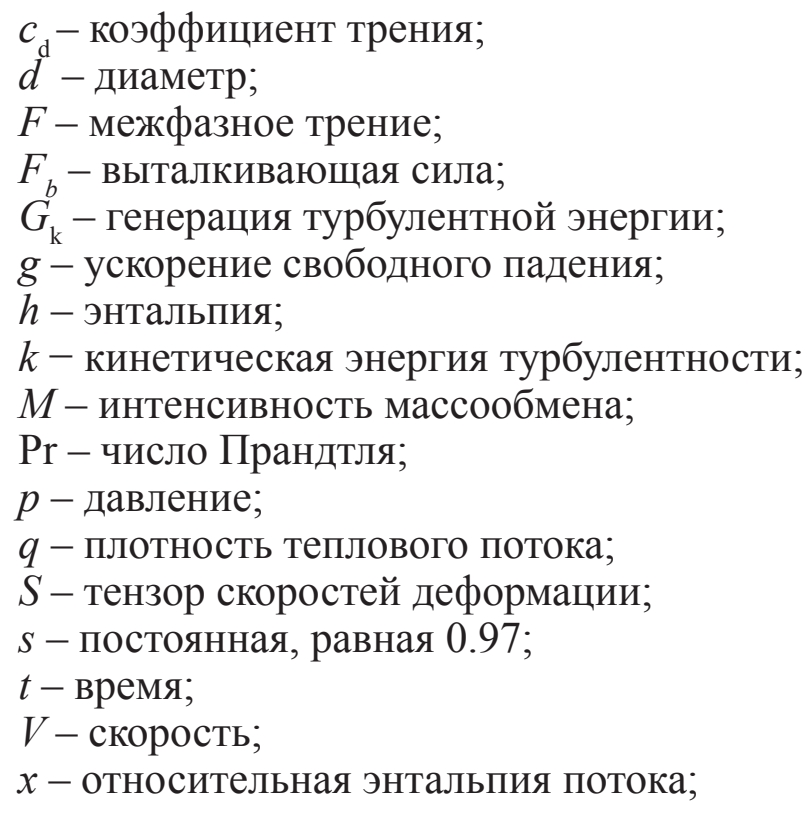

\section{Введение}

Межканальное взаимодействие теплоносителя оказывает значительное влияние на гидродинамику потока, а именно способствует выравниванию полей тепловых и гидравлических параметров в тепловыделяющей сборке активной $\delta_{\mathrm{nm}}-$ тензор Кронекера второго ранга;

$\varepsilon-$ скорость диссипации;

$\mathrm{k}$ - орт;

$\mu-$ вязкость;

$\rho-$ плотность;

$\rho \mathrm{w}$ - массовая скорость;

$\varphi$ - объемная фракция.

\section{Индексы:}

н.к - начало кипения;

к - критическая;

ц - центральная;

я - ячейка;

b - относится к пузырьку;

eff - эффективный;

$\mathrm{k}$ - фаза;

t - турбулентный;

$\varepsilon-$ относится к скорости диссипации.

зоны, что влияет на допустимый предел мощности реактора. Это взаимодействие вызвано как турбулентным перемешиванием, так и поперечными потоками теплоносителя между ячейками тепловыделяющей сборки и обеспечивает обмен массой, энергией и количеством движения между 
параллельными подканалами.

В работе [1] было сделано предположение о том, что энтальпия поперечного потока равна средней величине между значениями энтальпии теплоносителя в этих ячейках. Однако эта гипотеза не была подтверждена полученными ими же экспериментальными данными. Опыты по определению энтальпии поперечных потоков проводились в неизокинетических условиях. Результаты экспериментов показали, что величины энтальпии поперечных потоков зависят от режима течения потока и изменяются со сменой этих режимов. В пузырьковом режиме течения при паросодержании потока до 15 \% энтальпия поперечных потоков превышает энтальпию потока в ячейке-доноре. Это говорит о том, что при пузырьковом режиме течения в зазорах между стержнями в поперечном направлении движется в основном паровая фаза. При смене режима течения пузырькового на снарядный, энтальпия поперечного потока резко падает. Это можно объяснить тем, что при переходе к снарядному режиму в зазоре между стержнями в поперечном направлении движется уже в основном жидкая фаза.

При дальнейшем увеличении паросодержания потока в дисперсно-кольцевом режиме энтальпия поперечного потока вновь возрастает относительно энтальпии ячейки-донора, т.е. вновь преобладает в поперечном потоке движение паровой фазы.

Похожие результаты получены авторами работы [2], где исследование было проведено для стержневой сборки квадратной формы с квадратным расположением стержней, характерным для реакторов PWR.

Качественно похожие результаты по энтальпии поперечных потоков между каналами были получены в работе [3], хотя при этом исследовалась интенсивность межканального перемешивания пароводяной смеси в двух взаимосвязанных каналов в неизотермическом режиме.

Смена квадратной решетки стержневой сборки на треугольную, как оказывается, кардинально не меняет закономерности течения двухфазного потока. Авторы работы [4] исследовали межканальное взаимодействие воздушно-водяного потока (имитирующего пароводяной поток) в стержневой сборке треугольной геометрии. Ос- новной вывод исследования сводится к обнаружению усиления межканального взаимодействия воздушно-водяного потока в области перехода от снарядного к кольцевому режиму течения.

Еще одно исследование стержневой сборки с квадратной решеткой проведено авторами работы [5]. Здесь исследовалось течение пароводяной смеси в обогреваемом пучке стержней. Авторы так же обнаружили усиление активности межканального обмена двухфазного потока при переходе от снарядного к кольцевому режиму течения.

Слуцкер В.П. и другие [6] экспериментально исследовали перетоки теплоносителя при течении однофазного и двухфазного потоков. Были разработаны зависимости для определения интенсивности межканального обмена в различных режимах течения двухфазного потока. Эти зависимости так же показывают увеличение интенсивности межканального обмена двухфазного потока при переходе от снарядного к кольцевому режиму течения.

Межканальные перетоки присутствуют практически во всех режимах течения пароводяного потока. Уточнение значения энтальпии поперечных потоков в пучках стержней может существенно способствовать усовершенствованию расчетных программ. В данной работе исследовалась область течения воды при давлениях близких к критическому, при этом диапазон исследования начинался от течения однофазной жидкости, различных режимов двухфазного потока и вплоть до кризиса теплоотдачи при кипении. В качестве объекта исследования выбрана шестигранная семистержневая сборка, диаметр стержней 6 мм, шаг между стержнями 8 мм, обогреваемая длина $1 \mathrm{M}$.

Параметры исследования изменялись в таком диапазоне:

- массовая скорость $\rho w_{\text {п }}=1500 \frac{\kappa \Gamma}{\mathrm{M}^{2} \mathrm{c}}$;

- давление $p=9$ МПа, 14 МПа;

- плотность теплового потока $q=1,5 \frac{\mathrm{MBT}}{\mathrm{M}^{2}}$;

- относительная энтальпия потока в ячейкедоноре $x_{\text {я }}=-0,25 \ldots+0,30$. 
Было проведено численное моделирование процесса течения двухфазного потока с целью изучения энтальпии потоков смешения между ячейками пучка. Поперечное сечение пучка представлено на рис. 1.

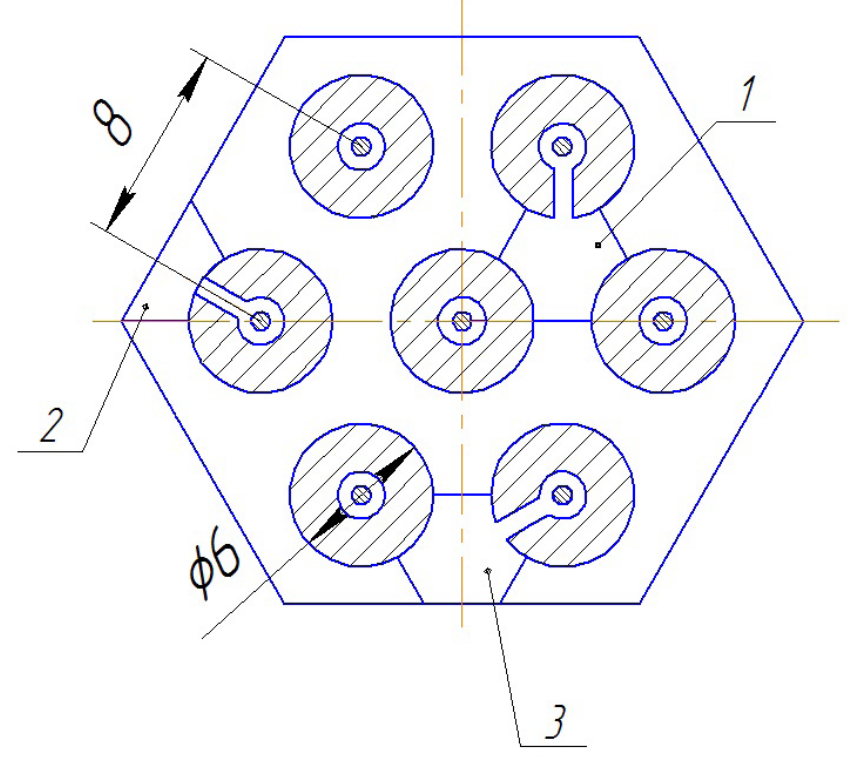

Рис. 1. Поперечное сечение пучка стержней.

Сечение пучка (рис. 1) условно разбивалось на 3 типа ячеек - центральную 1, боковую 2 и угловую 3. Моделирование энтальпии потоков смешения проводилось для центральной ячейки.

Математическая модель. При моделировании двухфазного потока использовалась модель [7], которая была модифицирована на основе полученных в работе экспериментальных данных.

Математическая модель двухфазного потока включает уравнение неразрывности, уравнение движения и уравнение энергии для каждой фазы, уравнения для кинетической энергии турбулентности и скорости диссипации энергии. Для замыкания системы уравнений используются уравнения для турбулентной вязкости и для эффективных турбулентных чисел Прандтля.

Уравнение неразрывности:

$\frac{\partial \rho_{k} \varphi_{k}}{\partial t}+\operatorname{div}\left(\rho_{k} \varphi_{k} V_{k}\right)=M_{k}$,

где $\rho_{\mathrm{k}}, \varphi_{\mathrm{k}}, V_{k}-$ плотность, объемная фракция и скорость каждой фазы, $k=1,2$.

Уравнение движения для каждой фазы:

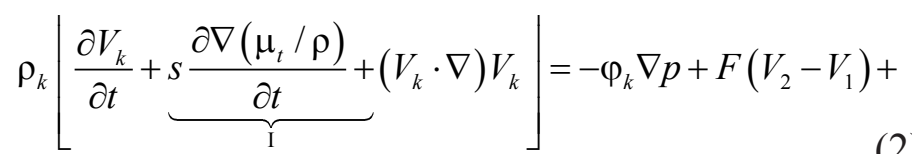

$+\nabla\left[\mu_{k}^{e f f}\left(\nabla V_{k}+\left(\nabla V_{k}\right)^{T}-\frac{2}{3} \nabla \cdot V_{k} \delta_{n m}\right)\right]+F_{b} \overrightarrow{\mathrm{k}}$,

где $\nabla V_{k}-$ тензорный градиент, который преобразует вектор (тензор первого ранга) в тензор второго ранга, $\left(\nabla V_{k}\right)^{T}-$ сопряженный (транспонированный) тензорный градиент, в последнем слагаемом $\nabla$ перед квадратными скобками - тензорная дивергенция, которая преобразует тензор скоростей деформаций второго ранга в вектор.

$F_{b}=\rho_{k} g$,

$F=0.75 \frac{c_{d} \rho_{1} \varphi_{1} \varphi_{2}}{d_{b}}\left|w_{r}\right|$.

Коэффициент трения находится по формулам:

$c_{d}=\left\{\begin{array}{cc}6.3 / \mathrm{Re}_{b}^{n_{1}} & \mathrm{Re}_{b}>100, \mathrm{We} \leq 8 \\ 2.67 & \mathrm{Re}_{b}>100, \mathrm{We}>8 \\ \mathrm{We}^{n_{2}} / 3.0 & \mathrm{Re}_{b}>2065.1 / \mathrm{We}^{n_{3}}\end{array}\right\}$,

где численное значение коэффициентов $n 1, n 2$ и $n 3$ будет определено из экспериментальных данных.

Уравнение энергии [8]:

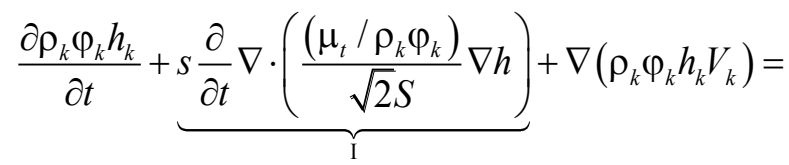

$I=\nabla\left(\frac{\mu_{k}^{e f f}}{\operatorname{Pr}_{k}^{e f f}} \varphi_{k} \nabla h_{k}\right)+S_{h}$.

Для замыкания уравнений турбулентного течения используется модель турбулентности. В настоящей работе использовалась RNG $k$ - $\varepsilon$ модель турбулентности.

Турбулентная вязкость определяется по формуле:

$\mu_{k t}=\frac{1}{24 \sqrt{15}}\left[\frac{\left(4 k+3 \sqrt{6 \pi C_{K}^{3} \varepsilon \mu_{k} / \rho_{k}}\right)^{2}}{C_{K}^{3 / 2} \varepsilon}-216 C_{K}^{3 / 2} \mu_{k} / \rho_{k}\right]$,

где $C_{K}=1,605$ - ренормгрупповое значение константы Колмогорова. 
Уравнение для кинетической энергии турбулентности:

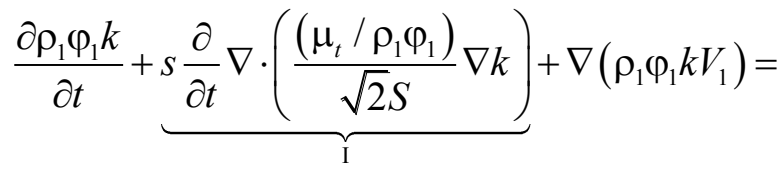

$$
\begin{aligned}
& =\nabla\left(\frac{\mu_{1}^{\text {eff }}}{\operatorname{Pr}_{k}} \varphi_{1} \nabla k\right)+S_{k},
\end{aligned}
$$

где I - дополнительное слагаемое, учитывающее нестационарность турбулентных процессов $[9$, $10]$.

Уравнение для скорости диссипации:

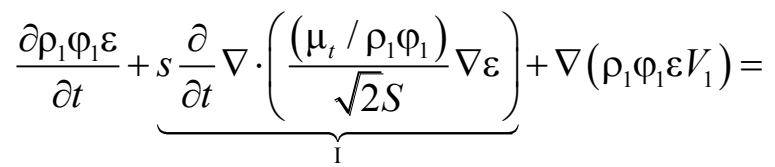

$$
\begin{aligned}
& =\nabla\left(\frac{\mu_{1}^{e f f}}{\operatorname{Pr}_{\varepsilon}} \varphi_{1} \nabla \varepsilon\right)+S_{\varepsilon} \text {. }
\end{aligned}
$$

Генерация турбулентной энергии определяется в виде:

$$
G_{k}=\mu_{t 1}\left(\nabla V_{1}+\left(\nabla V_{1}\right)^{T}-\frac{2}{3} \nabla \cdot V_{1} \delta_{n m}\right)^{2} .
$$

Для того чтобы проверить работоспособность

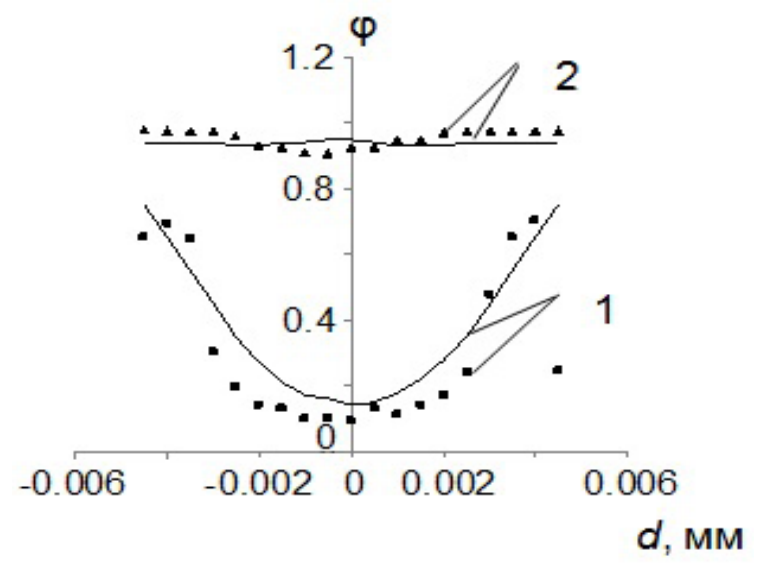

a) предложенной математической модели были проведены сравнительные расчеты. Для проведения тестовых расчетов были использованы исходные данные работы [11]. Расчет проводился для течения воды в вертикальном канале диаметром 10 мм и длинной 1 м для двух давлений 14 МПа и 18 МПа и с параметрами на входе: массовая скорость $500 \kappa г /\left(\mathrm{M}^{2} \cdot \mathrm{c}\right), 900 \kappa \Gamma /\left(\mathrm{M}^{2} \cdot \mathrm{c}\right)$, температура воды $458 \mathrm{~K}$ и $465 \mathrm{~K}$. Плотность теплового потока на стенке 0,5 МВт/м². Результаты расчетов истинного объемного паросодержания сравнивались с экспериментальными данными, представленными в работе [11] и приведены на рис. 2. Видно, что модель адекватно описывает поведение двухфазного потока при различных давлениях. Как для давления $14 \mathrm{MПа,} \mathrm{так} \mathrm{и} \mathrm{для} 18 \mathrm{MПа,} \mathrm{на} \mathrm{выходе}$ получены поперечные профили истинного объемного паросодержания. Сначала генерируемый пар накапливается и движется у стенок трубы. При возрастании относительной энтальпии увеличивается выброс пара в ядро потока и, вследствие этого, наблюдается равномерный профиль паросодержания на выходе из канала (рис. 2, $a$, режим 2).

При давлении 18 МПа на выходе из канала профиль паросодержания имеет седловидную

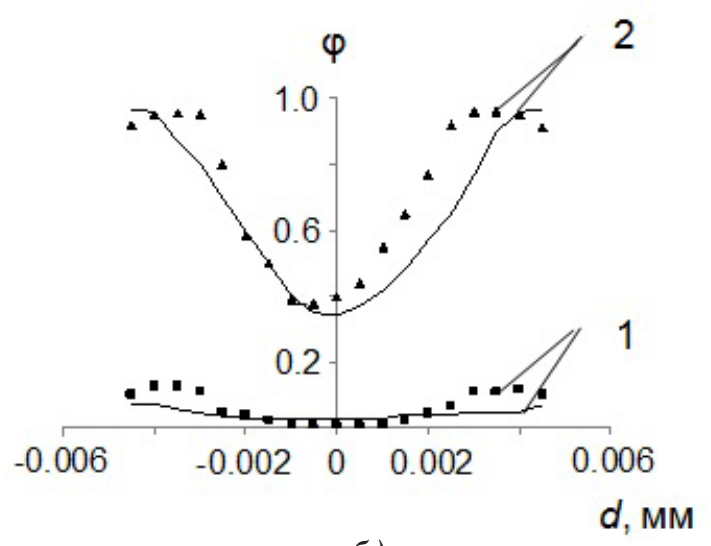

б)

Рис. 2. Распределение истинного объемного паросодержсания на выходе из трубы:

$$
\begin{aligned}
& \text { a) } p=14 \mathrm{MПа,} \rho w_{n}=500 \frac{\mathrm{\kappa} \Gamma}{\mathrm{M}^{2} \mathrm{c}}, q=0,5 \frac{\mathrm{MBT}}{\mathrm{M}^{2}}, 1-x=-0,019,2-x=0,219 ; \\
& \text { б) } p=18 \mathrm{MПа,} \rho w_{n}=900 \frac{\mathrm{\kappa} \Gamma}{\mathrm{M}^{2} \mathrm{c}}, q=0,5 \frac{\mathrm{MBT}}{\mathrm{M}^{2}}, 1-x=-0,04,2-x=0,146 .
\end{aligned}
$$

Точки-результаты эксперимента [11], линия-результат моделирования. 
форму, что свидетельствует о режиме развитого пузырькового течения (рис. 2, б).

Сравнение экспериментальных и расчетных данных показало, что для давления 14 МПа оптимальное значение параметров составляет: $n_{1}=0,402, n_{2}=1,4, n_{3}=2,72$. При давлении 18 МПа значение параметров составляет: $n_{1}=0,423, n_{2}=1,2, n_{3}=2,9$. Таким образом, используя значения параметров $n_{1}=0,385, n_{2}=$ $1,9, n_{3}=2,6$, которые получены в работе [12] до 14 МПа были предложены следующие обобщающие зависимости для определения коэффициентов во всем исследованном диапазоне изменения давления от 14 до $18 \mathrm{MПа:}$

$$
\begin{gathered}
n_{1}=0.1447+0.02475 p-0.0005417 p^{2}, \\
n_{2}=8.4333-0.7 p+0.01667 p^{2}, \\
n_{3}=1.2+0.135 p-0.0028 p^{2} .
\end{gathered}
$$

Результаты расчета. Результаты расчетов при течении теплоносителя в пучке стержней режимов с давлением $9 \mathrm{MПа} \mathrm{и} 14$ МПа с массовой скоростью $1500 \kappa \Gamma /\left(\mathrm{M}^{2} \cdot \mathrm{c}\right)$, плотностью теплового потока 1,5 МВт/м² представлены на рис. 3, 4. Вертикальными линиями показан переход от одного режима течения к другому, а именно начало кипения, переход от пузырькового к снарядному режиму, от снарядного к диспресно-кольцевому и критическое значение паросодержания, после которого наблюдается кризис теплоотдачи.

Что касается полученных результатов исследования, то на характер изменения энтальпии потока смешения большое влияние оказывает режим течения теплоносителя. Границы режимов течения определялись согласно работе [13].

В пределах однофазного потока и пузырькового течения двухфазного потока наблюдается монотонный рост энтальпии поперечного потока из центральной ячейки. В течении практически всего диапазона пузырькового режима наблюдается рост энтальпии поперечных потоков между центральной и боковой ячейками по отношению к энтальпии потоков в этих ячейках и получающаяся разница энтальпий достигает 100...200 кДж/кг. Этот монотонный рост сменяется резким падением энтальпии поперечного потока при переходе к снарядному режиму течения (на $100 . . .120$ кДж/кг).
Дальнейший рост энтальпии потока в центральной ячейке вновь сопровождается монотонным ростом энтальпии поперечных потоков вплоть до перехода к дисперсно-кольцевому режиму течения. При этом разница энтальпии по-

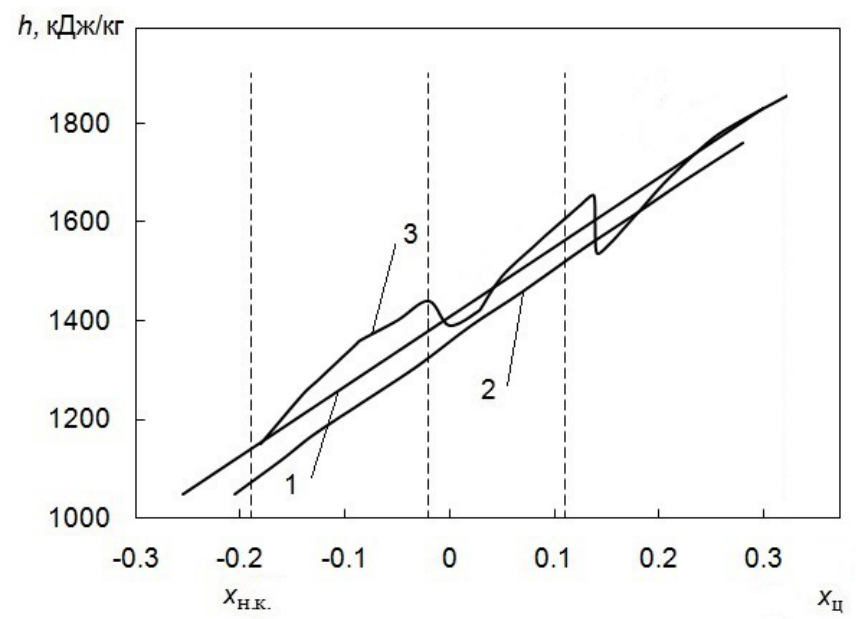

Рис. 3. Изменение энтальпии потока смешения, центральная ячейка-донор, $\rho w_{\mathrm{n}}=1500 \frac{\mathrm{\kappa} \Gamma}{\mathrm{M}^{2} \mathrm{c}}, p=9$ МПа, $q=1.5 \frac{\mathrm{MBT}}{\mathrm{M}^{2}}:$

1 - энтальпия потока в центральной ячейке, 2 - энтальпия потока в боковой ячейке, 3 -расчетная энтальпия потока смешения.

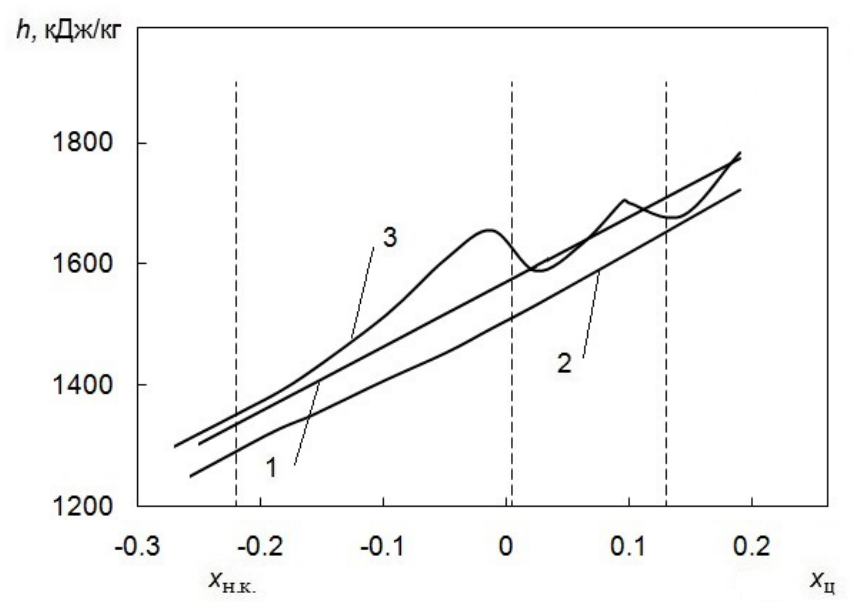

Рис. 4. Изменение энтальпии потока смешения, центральная ячейка-донор, $\rho w_{\mathrm{n}}=1500 \frac{\kappa \Gamma}{\mathrm{M}^{2} \mathrm{c}}, p=14$ МПа, $q=1.5 \frac{\mathrm{MBT}}{\mathrm{M}^{2}}:$

1 - энтальпия потока в центральной ячейке, 2 - энтальпия потока в боковой ячейке, 3 -расчетная энтальпия потока смешения. 
перечного потока и энтальпий потоков в смежных ячейках достигает 50..100 кДж/кг. Т.е. в рассматриваемой области наблюдается стремление паровой фазы переместится к центру каналу.

Дальнейшее увеличение энтальпии потока в центральной ячейке характеризуется монотонным ростом энтальпии поперечного потока вплоть до предкризисных режимов теплоотдачи. Полученные данные хорошо согласуются с экспериментальными данными.

\section{Выводы}

1. На основе экспериментальных данных усовершенствована математическая модель расчета двухфазных потоков. Данная математическая модель дает возможность достаточно точно прогнозировать динамику изменения энтальпии поперечных потоков при течении двухфазного теплоносителя в теплонапряженных каналах активной зоны реактора.

2. На значение энтальпии потока смешения значительное влияние оказывает режим течения двухфазного потока. При смене режимов течения наблюдается резкое снижение значений энтальпии потока смешения между центральной и боковой ячейками.

3. В условиях сформировавшегося режима течения - пузырькового, снарядного либо дисперсно-кольцевого, наблюдается дрейф паровой фазы в наиболее высокоскоростную центральную область пучка. При этом превышение энтальпии потока смешения над величиной энтальпии в наиболее горячей центральной ячейке пучка достигает 100...200 кДж/кг.

\section{ЛИТЕРАТУРА}

1. Ricque $R$. Determination des distributions de debit massique et d'enthalpie entre les souscanaux d'une grappe chaffante // Colloque francosoviétique sur la thermohydraulique des reacteurs a EAU. - 1978. - P. 1-25.

2. Lahey R.T. Out of pile subchannel measurements in a nine rod bundle for water at 1000 psia // Progress in Heat and Mass Transfer. - 1972. vol.6. - P. 172-177.
3. Rowe D.S. Experimental study of mixing between rod-bundle fuel element flow channels during boiling // Trans. Of ANS. - 1967. - №2 . v.10. - P. 655-656.

4. Rudzinski K.F. Turbulent mixing for air water flows in simulated rod bundle geometries // The Canadian Journal of Chemical Engineering. - 1972. №2. - v.50. - P. 297-299.

5. Kuldip $S$. Two phase mixing for annular flow in simulated rod bundle geometries // Nuclear Science and Engineering. - 1973. - №4. - v.50. - P. 382-387.

6. Слуикер В.П. Экспериментальное исследование перемешивания при течении однофазного и двухфазного теплоносителя // Семинар ТФ-78 «Теплофизические исследования для обепечения надежности и безопасности ядерных реакторов водо-водяного типа». - Буда-пешт, 1978. - том 2. - С.823-836.

7. Скицко А.И. Моделирование двухфазного потока // Энергетика: экономика, технологии, екология. - 2008. - №1. - С. 17-21.

8. Dolinsky A.A., Kovetskaya M. M., Skitsko A. I., Avramenko A. A., Basok B. I. Nonstationary heat transfer crisis in annular dispersed flows // Journal of Engineering Thermophysics. - 2008. - vol.17. - №2. - P. 126-129

9. Авраменко А.A. Ренормгрупповой анализ нестационарной турбулентности // Доклады НАН Украины. - 2007. - №12. - С. 88-93

10. Авраменко А.А. Апробация ренормгрупповой модели нестационарной турбулентности // Доклады НАН Украины. - 2011. - №5. - С. 88-93

11. Кириллов П.Л., Ложкин В.В., Смирнов Ю.А., Судницыьн О.А. Измерение локальных значений истинного объемного паросодержания в обогреваемой трубе методом акустического зондирования // Теплоэнергетика. - 1984. - №11. C.25-27

12. Скіųько O.I. Теплообмін та гідродинаміка потоків у вертикальних каналах з фазовим переходом в умовах впливу збурюючих факторів: автореф. дис. на здобуття наук. ступеня канд. техн. наук : спец. 05.14.06 «Технічна теплофізика та промислова теплоенергетика» / O.І. Скі-цько. Київ, 2011. - 20 с. 
13. Исследование вопросов гидродинамики и теплофизики реакторов и контуров АЭС включая переходные и аварийные режимы. Метод расчета поперечного перемешивания при течении однои двухфазных потоков в стержневых тепловыде-

\section{EFFECT OF REGIME PARAMETERS ON E NTHALPY OF CROSS-FLOW BETWEEN THE CELLS OF THE ROD BUNDLE}

\section{A. Avramenko, E. Kondratieva, M. Kovetskaya, A. Tyrinov}

Institute of Engineering Thermophysics of the National Academy of Sciences of Ukraine, 03057, Kiev, vul. Zhelyabova 2a, Ukraine.

This paper analyzes the processes of heat transfer for the two-phase flow in the seven-rod assembly. Computer simulations were performed for the enthalpy of cross-flow between the cells of the rod bundle under subcritical pressure. Numerical study of the processes was based on the k- $\varepsilon$ RNG turbulence model. Results for the mixing flow enthalpy in central rod were analyzed. Regime parameters are ranged from a single-phase flow up to the subcritical heat transfer in two-phase flows. Influence of flow regime changeover on enthalpy variation was imnvestigated. References 14, fig.4.

Key words: numerical modeling, seven-rod assembly, enthalpy of cross-flow.

1. Ricque $R$. Determination des distributions de debit massique et d'enthalpie entre les souscanaux d'une grappe chaffante // Colloque francosoviétique sur la thermohydraulique des reacteurs a EAU. - 1978. - P.1-25. ляющих сборках / Отчет 27.610 От. Инв. №270027-744, предприятие п/я А-7291. - М., 1980. $-57 \mathrm{c}$.

14. Хвюитт Дж., Холл-Тейлор Н. Кольцевые двухфазные течения / М. : Энергия, 1974. - 407 с.

2. Lahey R.T. Out of pile subchannel measurements in a nine rod bundle for water at 1000 psia // Progress in Heat and Mass Transfer. - 1972. vol.6. - P.172-177.

3. Rowe D.S. Experimental study of mixing between rod-bundle fuel element flow channels during boiling // Trans. Of ANS. - 1967. - №2 . v.10. - p.655-656.

4. Rudzinski K.F. Turbulent mixing for air water flows in simulated rod bundle geometries // The Canadian Journal of Chemical Engineering. - 1972. - №2. - v.50. - P.297-299.

5. Kuldip $S$. Two phase mixing for annular flow in simulated rod bundle geometries // Nuclear Science and Engineering. - 1973. - №4. - v.50. P.382-387.

6. Slutsker V.P. Experimental research of interfusion at the flow of monophase and diphasic coolant-moderator // Seminar TF-78 «Teplofizicheskie issledovaniya dlya obepecheniya nadezhnosti i bezopasnosti yadernyih reaktorov vodo-vodyanogo tipa». - Budapesht, 1978. - vol 2. - P.823-836. (Rus.)

7. Skitsko A.I. The modeling of two-phase flow // Energetika: ekonomika, tehnologii, ekologiya. 2008. - №1. - P. 17-21. (Rus.)

8. Dolinsky A.A., Kovetskaya M. M., Skitsko A. I., Avramenko A. A., Basok B. I. Nonstationary heat transfer crisis in annular dispersed flows // Journal of Engineering Thermophysics. - 2008. - vol.17. - №2. - P. 126-129 
9. Avramenko A.A. Renormalization group analysis of non-stacionary turbulence // Reports of NAS Ukraine. - 2007. - №12. - P. 88-93. (Rus.)

10. Avramenko A.A. Testing of the renormalization group model non-stacionary turbulence // Reports of NAS Ukraine. - 2011. - №5. - P. 88-93. (Rus.)

11. Kirillov P.L., Lozhkin V.V., Smirnov Y.A., Sudnitsyn O.A. Measuring of local values of veritable by volume of contents of steam in the heated pipe the method of the acoustic sounding. // Teploenergetika. - 1984. - №11. - P. 25-27. (Rus.)

12. Skitsko A.I. Heat transfer and hydrodynamics of flows in vertical channels with a phase transition under the influence of disturbing factors. Manuscript. Thesis for the degree of candidate of technical sciences, specialty 05.14.06 - Engineering thermophysics and industrial heat power Engineering / Skitsko A.I. - Kiev, 2011. - 20 p. (Rus.)

13. Including research of questions of hydrodynamics and teplofphysic reactors and contours of AES transient and emergency behaviors. Method of calculation of transversal interfusion at the flow of monophase and diphasic streams in the cored assembling / Otchet 27.610 Ot. Inv. \#270-027-744, predpriyatie p/ya A-7291. - M., 1980. - 57 p. (Rus.) 14. Hvyuitt Dzh., Holl-Teylor N. Circular diphasic flows / M. : Energiya, 1974. - 407 p. (Rus.)

Получено 31.03.2015 Received 15.03.2015 